\title{
Scaffolds for Dental Pulp Tissue Engineering
}

\section{K.M. Galler ${ }^{1 *}$, R.N. D'Souza ${ }^{2}$, J.D. Hartgerink ${ }^{3}$, and G. Schmalz ${ }^{1}$}

${ }^{1}$ University of Regensburg, Department of Restorative Dentistry and Periodontology, Regensburg, Germany; ${ }^{2}$ Baylor College of Dentistry, Department of Biomedical Sciences, Texas A\&M, Dallas, USA; and ${ }^{3}$ Rice University, Departments of Chemistry and Biomedical Engineering, Houston, TX, USA; *corresponding author, kerstin.galler@klinik .uni-regensburg.de

Adv Dent Res 23(3):333-339, 2011

\section{ABSTRACT}

For tissue engineering strategies, the choice of an appropriate scaffold is the first and certainly a crucial step. A vast variety of biomaterials is available: natural or synthetic polymers, extracellular matrix, self-assembling systems, hydrogels, or bioceramics. Each material offers a unique chemistry, composition and structure, degradation profile, and possibility for modification. The role of the scaffold has changed from passive carrier toward a bioactive matrix, which can induce a desired cellular behavior. Tailor-made materials for specific applications can be created. Recent approaches to generate dental pulp rely on established materials, such as collagen, polyester, chitosan, or hydroxyapatite. Results after transplantation show soft connective tissue formation and newly generated dentin. For dentinpulp-complex engineering, aspects including vascularization, cell-matrix interactions, growth-factor incorporation, matrix degradation, mineralization, and contamination control should be considered. Self-assembling peptide hydrogels are an example of a smart material that can be modified to create customized matrices. Rational design of the peptide sequence allows for control of material stiffness, induction of mineral nucleation, or introduction of antibacterial activity. Cellular responses can be evoked by the incorporation of cell adhesion motifs, enzymecleavable sites, and suitable growth factors. The combination of inductive scaffold materials with stem cells might optimize the approaches for dentin-pulp complex regeneration.

0 ver the past two decades, tissue engineering and regenerative medicine have become increasingly important areas of research. With a combination of biomaterials, competent (stem) cells, and inductive growth and differentiation factors, the goal is to improve or, ideally, fully restore the functions of diseased tissues or organs. What seemed like science fiction only 20 years

\section{DOI: $10.1177 / 0022034511405326$}

(C) International \& American Associations for Dental Research ago is within the realm of possibility today, and various tissue engineering products are already being applied in clinical practice. Spectacular developments include the generation of induced pluripotent stem cells (Takahashi and Yamanaka, 2006), a beating heart in a petri dish (Jakab et al., 2008), the first successful transplantation of a tissue-engineered trachea (Macchiarini et al., 2008), or, in the field of dentistry, the first bioengineered tooth germ, which developed and erupted in the oral cavity as a functional replacement (Ikeda et al., 2009). Advances in tissue engineering are translating into medical practice and changing therapeutic strategies. The area of material science has contributed considerably to this process. With the development of more versatile and sophisticated biomaterials, scaffolds have transitioned from bioinert passive cell carriers and mere delivery vehicles to bioactive and instructive matrices, which can be controlled in all aspects of material behavior. Although dentistry is one of the disciplines which have long capitalized on the use of biomaterials, these serve mainly to replace lost tissues and restore their function. However, tissue engineering approaches in dentistry are evolving. In the fields of periodontology and oral surgery, regenerative strategies have already been implemented in daily practice. Commercially available products for bone and periodontal tissue regeneration are available to clinicians, and have improved treatment outcomes and success rates (Costello et al., 2010; Villar and Cochran, 2010). More recently, engineering of dental pulp and dentin with pulp-derived stem cells has made considerable progress (Cordeiro et al., 2008; Huang et al., 2010; Sakai et al., 2010). With a wide range of biomaterials choices, the question is how far we can optimize our strategies for dentin-pulp complex engineering with the help of novel and smart biomaterials, which are tunable and tailor-made for this specific approach.

\section{BIOMATERIALS FOR DENTAL PULP ENGINEERING}

For most regenerative strategies, an organic scaffold is used to provide a surface on which cells may adhere, grow, and spatially organize. Various classes of biomaterials are available to the tissue engineer (Table 1).

An ideal scaffold should facilitate the attachment, migration, proliferation, and three-dimensional spatial organization of the cell population required for structural and functional replacement of the target tissue. Biocompatibility is of utmost importance to prevent adverse tissue reactions. Since the host cells will, in any case, interact with the scaffold, biodegradability should be tun-

\section{Key Words}

scaffolds, dental tissue engineering, dental stem cells, hydrogel, selfassembling peptides, regenerative medicine. 
Table 1. Biomaterials for Tissue Engineering

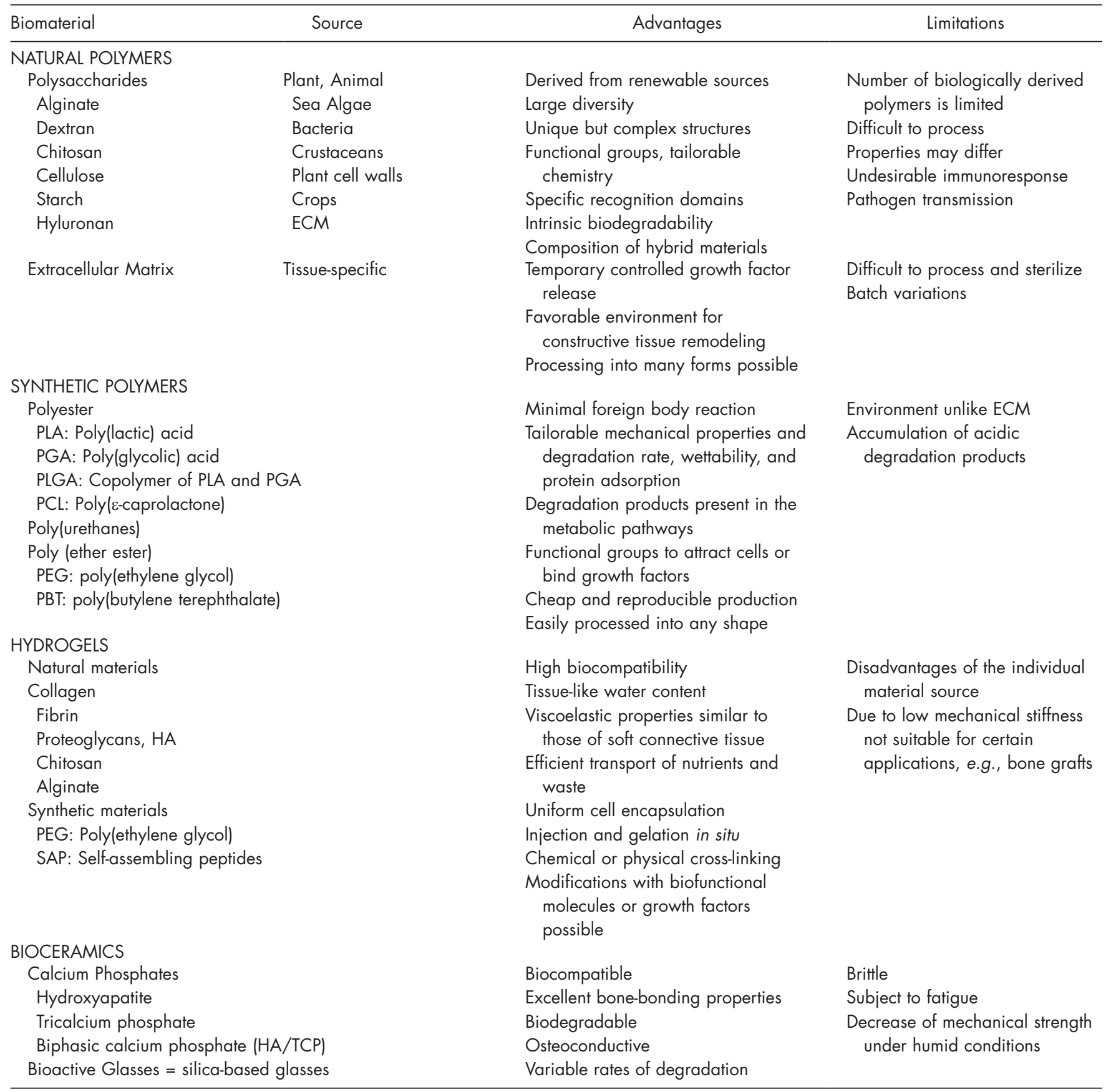

able, to facilitate constructive remodeling, which is characterized by scaffold degradation, cellular infiltration, vascularization, differentiation and spatial organization of the cells, and, eventually, replacement of the scaffold by the appropriate tissues.

The two categories of materials that are most commonly used in tissue engineering are synthetic polymers such as poly(lactic) acid (PLA) and poly(glycolic) acid (PGA) (Vacanti et al., 1998; Gloria et al., 2010), and matrices derived from biological sources such as reconstituted collagen (Glowacki and Mizuno, 2007). Table 2 provides an overview of biomaterials that have been uti- lized particularly for dental pulp engineering. Early studies utilized human dental pulp cells on PGA fibers, collagen I, and alginate, where a pulp-like tissue was observed with the PGA scaffolds after 45 to 60 days of in vitrocell culture (Mooney et al., 1996; Bohl et al., 1998). After isolation and in vitro characterization of dental pulp stem cells from deciduous teeth and third molars, the cells were mixed with hydroxyapatite/tricalcium phosphate (HA/TCP), and the formation of dentin, bone, and dentin-pulp-like complexes was observed (Gronthos et al., 2000; Miura et al., 2003). A comparison of different materials (collagen 
Table 2. Biomaterials Utilized for Dental Pulp Tissue Engineering

\begin{tabular}{|c|c|c|c|}
\hline Material & Engineering Approach & Result & Reference \\
\hline $\mathrm{HA} / \mathrm{TCP}$ & $\begin{array}{l}\text { Stem cells from dental pulp } \\
\text { (SHED, DPSC) mixed with HA/ } \\
\text { TCP powder transplanted into } \\
\text { nude mice }\end{array}$ & $\begin{array}{l}\text { Generation of dentin or bone } \\
\text { (SHED) and dentin-pulp-like } \\
\text { complexes (DPSC) }\end{array}$ & $\begin{array}{l}\text { Gronthos et al., } 2000 \\
\text { Miura et al., } 2003\end{array}$ \\
\hline Collagen I with Dmp-1 & $\begin{array}{l}\text { Collagen scaffolds laden with } \\
\text { Dmp-1 and dental pulp stem } \\
\text { cells were placed in dentin } \\
\text { disks with a simulated furcal } \\
\text { perforation and transplanted } \\
\text { subcutaneously into nude mice }\end{array}$ & $\begin{array}{l}\text { Formation and organization of } \\
\text { new pulp tissue }\end{array}$ & Prescott et al., 2008 \\
\hline PLA & $\begin{array}{l}\text { SHED seeded onto PLA scaffolds } \\
\text { into tooth slices, subcutaneous } \\
\text { transplantation into nude mice }\end{array}$ & $\begin{array}{l}\text { Formation of vascularized soft } \\
\text { connective, pulp-like tissue } \\
\text { and new tubular dentin }\end{array}$ & $\begin{array}{l}\text { Cordeiro et al., } 2008 \\
\text { Sakai et al., } 2010\end{array}$ \\
\hline PLGA & $\begin{array}{l}\text { SCAP and DPSC seeded onto } \\
\text { PLGA into root canals sealed } \\
\text { with MTA on one side, } \\
\text { subcutaneous implantation into } \\
\text { nude mice for } 3-4 \text { months }\end{array}$ & $\begin{array}{l}\text { Formation of a pulp-like tissue, } \\
\text { deposition of dentin along } \\
\text { the root canal wall }\end{array}$ & Huang et al., 2010 \\
\hline
\end{tabular}

I and III, alginate, and chitosan) rendered best results in terms of proliferation and mineralization activity on type I collagen. Highly promising results were achieved by Nör's group (Cordeiro et al., 2008), which demonstrated the formation of a vascularized pulp-like tissue, odontoblast-like cells, and newly generated dentin after seeding SHED cells onto PLA in dentin disks. Similarly, Huang et al. observed soft tissue and deposition of new dentin after transplantation of stem cells from apical papilla (SCAP) onto PGLA in an empty root canal space (Huang et al., 2010). In summary, collagen I and the synthetic polymers showed the most favorable results among the materials studied for this particular application. In terms of biocompatibility and degradation, all the above-described materials exhibited satisfactory results. Synthetic polyester such as PLA, PGA, and their co-polymers are non-toxic and biocompatible, they degrade by hydrolysis, and have gained FDA approval for numerous applications (Chan and Mooney, 2008). Collagen is biocompatible and degradable by enzymes, but natural polymers are often difficult to process and are afflicted with the risk of transmitting animal-associated pathogens or provoking an immunoresponse. Alginate, a polysaccharide derived from red algae, offers a mild cell encapsulation process, since it can be cross-linked via $\mathrm{Ca}^{2+}$. However, it degrades in a rather uncontrolled manner via dissolution, since the material is sensitive to calcium chelating compounds (Boontheekul et al., 2005). Chitosan is derived from chitin, a polysaccharide found in crustaceans. Because of its good biocompatibility and degradability via naturally occurring enzymes, it has been used for numerous tissue engineering applications (Jiang et al., 2008).

However, neither described category has all the structure and properties of an ideal material, which should most closely resemble the cells' physiological environment: natural extracellular matrix (ECM). The ECM acts as a structural support, but its role goes far beyond this. The ECM is a nanostructured environment that provides the chemical signals to modulate cellular behavior and reinforce a particular phenotype. Furthermore, the ECM is a dynamic environment and can be selectively degraded and remodeled by the cells living within it. Polymers like PLA have the advantage of being biodegradable, biocompatible, and inexpensive and easy to prepare. However, they lack the chemical information that is physiologically found in the ECM. In contrast, collagen offers the chemical and structural information of the ECM but is difficult to customize for specific applications. Because of its biological origin, purity and immune reaction can be of concern. An ideal scaffold should combine the best properties of each of these groups of biomaterials. These 

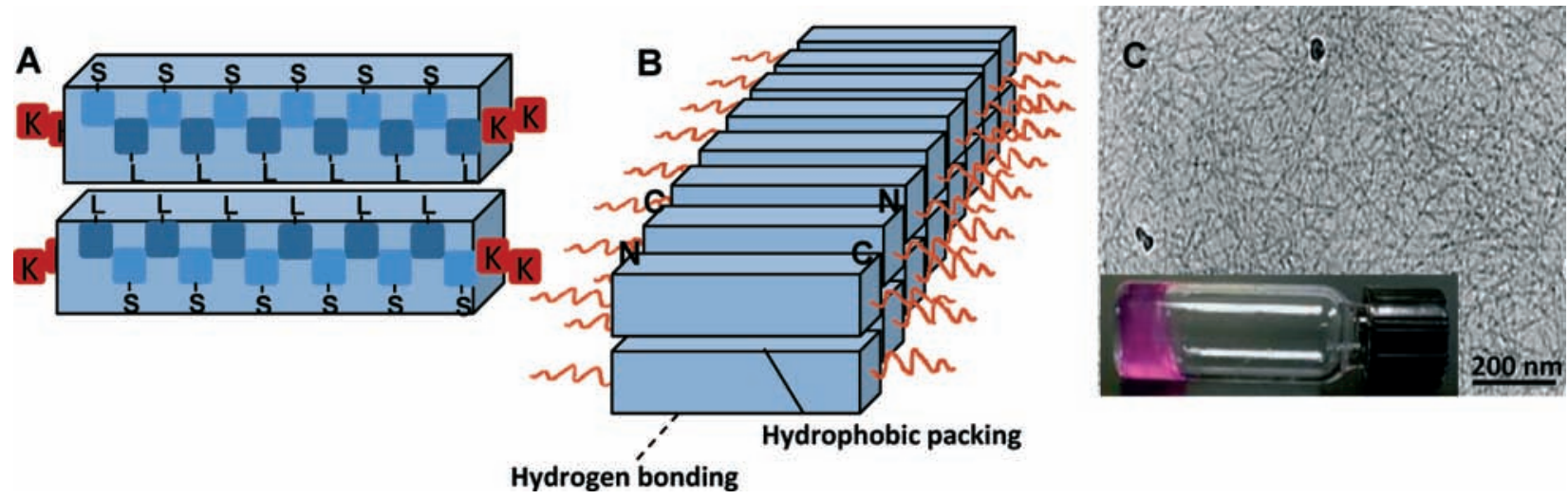

Figure. Schematic of multidomain peptide self-assembly. (A) The peptide monomers are made of a central block of alternating hydrophilic $(\mathrm{S}=$ serine) and hydrophobic ( $\mathrm{L}=$ leucine) residues. (B) Dimers form because of the tendency of the hydrophobic amino acids to shield from the water. Positively charged residues ( $\mathrm{K}=$ lysine) provide water solubility and aid in cross-linking and stabilization of the nanofibers after the addition of negatively charged ions, such as phosphate. The dimers string together, forming a nanofiber, which is stabilized by hydrogen bonding along the fiber axis. N: N-terminus. C: C-terminus. (C) The TEM image shows the nanofibrous network, macroscopically, and gelation is observed.

would be structurally similar to ECM at the nanoscale, be able to present complex molecular information to the cells, and be easy to modify for specific applications. To address these deficiencies, novel synthetic matrices are being developed for tissue engineering. Among these, peptide-based nanofibers are particularly promising because of their ease of synthesis, chemical diversity, and high control over various aspects of material behavior (Hartgerink et al., 2002; Zhang, 2003; Silva et al., 2004). Regarding dentin-pulp-complex engineering, the scaffold should allow us to address the particular challenges of this approach, including contamination control in the root canal, vascularization and innervation of a long and narrow space, the incorporation of growth and differentiation factors relevant to odontoblast differentiation, the support of mineral formation, and the possibility for creation of acellular matrices capable of recruiting resident stem cells in the respective tissues.

\section{SELF-ASSEMBLING PEPTIDES}

Self-assembling peptides (SAP; Fig.) are an excellent model of a material which can be modified and customized, and thus address the various requirements for a specific tissue-engineering approach. They are usually synthesized at 15 to 25 amino acids in length, which, based on their design, undergo self-assembly, generate nanofibrous networks, entrap water, and thus form hydrogels. Different concepts for self-assembling peptides exist; the multidomain peptide (MDP) system discussed here was developed in Dr. Hartgerink's laboratory. It features an ABA block motif, in which the central B block is made of alternating hydrophilic and hydrophobic amino acid residues, which provide the driving force for self-assembly. In water, they assemble on opposing sides of the peptide backbone, and dimers form because of the tendency of the hydrophilic residues to shield from the water. These dimers string together and form sandwich-like $\beta$-sheet nanofibers, $6 \mathrm{~nm}$ wide and $2 \mathrm{~nm}$ high, where hydrogen bonding occurs along the fiber axis (Dong et al.,
2007). The flanking region is made up of charged residues, which make the molecules water-soluble and offer the possibility of cross-linking via oppositely charged ions. Since the peptide chains are made of naturally occurring amino acids, the resulting materials are biocompatible and can be designed to be biodegradable.

Hydrogel systems in general offer advantages such as viscoelastic properties similar to those of soft connective tissues, fast diffusion of nutrients and metabolites, and the possibility of homogenous cell encapsulation. The use of multidomain peptides is furthermore advantageous because of an automated synthesis process, high control over the material properties, a wide range of chemical functionalities, and the possibility for tailoring toward specific applications. Single amino acids serve as building blocks which can be used in a modular fashion, and the peptide sequence determines the properties of the resulting material. Bioactive motifs can already be incorporated into these systems during the synthesis process. Further options for customization will be discussed in the sections below.

\section{BIODEGRADABILITY}

The organization of MDP molecules into $\beta$-sheet aggregates with poor water solubility and a fiber assembly process reminiscent of amyloid raises concerns that this material cannot be degraded in vivo and might not be suitable as a tissue engineering scaffold. This is underscored by the devastating effects of amyloid aggregates in the brain, causing Alzheimer's disease and dementia, or other organs such as the heart, kidney, and vascular system (Stefani, 2010). If susceptibility to proteolytic degradation is programmed into these $\beta$-sheet-forming peptides, MDPs can be adapted to requirements for biological applications. A hexapeptide containing the MMP-2 consensus cleavage motif LRG was successfully incorporated into the central block without altering the length of the peptide, gelation process, or viscoelastic properties. The resulting peptide was confirmed to 
be degraded by MMP-2 in vitro, and cell culture studies demonstrated that the cells started migrating into the hydrogel matrix if the cleavage site were present (Galler et al., 2010).

\section{CELL-MATRIX INTERACTIONS}

The first step of cell-matrix interaction, cell adhesion, can be mediated by various short peptide motifs, which mimic ligands on molecules abundant in natural ECM. It is particularly attractive to incorporate these motifs into self-assembling peptides, because this can be done as part of the synthesis process. Sequences derived from fibronectin include the integrin-binding tripeptide RGD (Ruoslahti, 1996), REDV (Massia and Hubbell, 1992), PHSRN (Aota et al., 1994), or KNEED (Wong et al., 2002). Similar motifs can be found in laminin (Yamada and Kleinman, 1992) and collagen (Bhatnagar et al., 1997). Other highly interesting sequences include short heparin-binding sequences, which can be utilized to link growth factors to the matrix. Heparin, a highly negatively charged glycosaminoglycan, can bind growth factors in the ECM, protect them from rapid degradation, and release them slowly in response to cellmediated matrix degradation. Consensus heparin-binding sequences have been described as XBBXBX or XBBBXXBX (where $\mathrm{X}$ is a hydrophobic amino acid and $\mathrm{B}$ a basic amino acid residue) (Cardin and Weintraub, 1989). With this indirect mechanism of binding, various growth factors can be incorporated into scaffolding systems. FGF-2 or TGF $\beta 1$ might be particularly interesting for the work with dental stem cells, since the former mainly stimulates cell proliferation, while the latter affects cell morphology and differentiation toward an odontoblast-like phenotype 100 (He et al., 2008). Heparin-mediated incorporation or growth factors can furthermore be utilized to address another highly important aspect in tissue engineering, namely, the supply of implanted cells with nutrients through new blood vessel formation and connection to the existing vascular network. Stimulation of vasculogenesis via heparin-bound vascular endothelial growth factor (VEGF) in self-assembling peptides has been demonstrated in in vivo applications (Rajangam et al., 2006, 2008).

\section{VISCOELASTIC PROPERTIES}

In living tissues, the elastic moduli span several orders of magnitude, ranging from $100 \mathrm{~Pa}$ in the brain to $950 \mathrm{kPa}$ in cartilage or tendon (Levental et al., 2007). In vitro experiments show that cell adhesion, morphology, and gene expression profiles change on chemically equivalent surfaces with different rigidities (Nemir and West, 2010). In general, cells tend to migrate from softer to stiffer environments (Wells, 2008). Whereas they appear most motile at intermediate stiffness, increased matrix moduli generally stimulate cellular differentiation, where the optimum has to be established individually for each cell type. Having a library of MDP's with a range of matrix moduli would be advantageous, since this might provide another means of controlling cell behavior. Previous work in Dr. Hartgerink's laboratory demonstrated how the mechanical properties of MDP hydrogels can be varied through the modification of the peptides' chemical functionality (Aulisa et al., 2009). Relatively minor changes in fiber surface chemistry (changing amino acid residues in the central block motif and/or the flanking region) resulted in changes in matrix rigidities. Highest moduli were achieved by the induction of covalent bond formation via cysteine disulfide bonds, which resulted in a 60 -fold increase in stiffness. Fine-tuning is furthermore possible by altering the peptide concentration, which can be adjusted between $0.1 \%$ and $4 \%$ by weight.

Apart from hydrogel stiffness, important aspects for biomedical applications are shear thinning behavior and shear recovery. For the material to be loaded into a syringe and injected through a needle, these characteristics would be highly desirable. Several of the MDP systems offer this feature. Oscillatory rheometry tests confirmed that, after the induction of sheer, the hydrogels undergo sheer recovery, where the storage modulus, a measure for gel stiffness, recovers to nearly $100 \%$ of the initial value in less than a minute, which makes these materials ideal candidates for biomedical applications requiring syringe injection.

\section{BIOMINERALIZATION}

During the synthesis of dentin and enamel, an organic matrix precedes the mineral produced by ameloblasts and odontoblasts. Non-collagenous proteins play a key role in the mineralization process, where negatively charged surfaces and phosphorylated serine residues attract $\mathrm{Ca}^{2+}$, initiate crystal growth, and control the orientation and elongation of the hydroxyapatite crystals. The main players are called SIBLINGS (small integrin binding ligand, N-linked glycoprotein), which include bone sialoprotein (BSP), osteopontin (OPN), dentin sialophosphoprotein (DSPP), dentin matrix protein-1 (DMP-1), and matrix extracellular phosphoprotein (MEPE). These organic components, commonly found in the matrix of mineralizing tissues, share the presence of the integrin-binding peptide RGD to mediate cell adhesion; they contain multiple serine-rich domains in $\beta$-sheet conformation for phosphorylation and display a high density of negative charge to initiate crystal nucleation (George et al., 1993; Tye et al., 2003). Short peptide sequences derived from DMP-1 have been identified, which display $\mathrm{Ca}$-induced self-assembly into $\beta$-sheet structures and provoke hydroxyapatite crystal growth (He et al., 2003). Features of these mineralization-inducing peptide motifs can be programmed into scaffolds. Selfassembling peptides offer the advantage that mineralization domains such as phosphorylated serines and acidic domains can be incorporated into the peptide monomers during synthesis. Groundbreaking work demonstrated that peptide-amphiphile molecules can be functionalized by incorporation of phosphorylated serine residues, which facilitates $\mathrm{Ca}^{2+}$-binding and $\mathrm{HA}$ crystal nucleation and growth along the fiber long axis (Hartgerink et al., 2001). Our previous work demonstrated mineral nucleation along the nanofibers of self-assembling peptides in the presence of dental stem cells (Galler et al., 2008). Utilizing these motifs for dental tissue engineering might facilitate the generation of the mineralized component of the dentinpulp complex. 


\section{CONTAMINATION CONTROL}

Tissue engineering approaches to regenerate dental pulp will always involve contamination control, since the causes of the loss of dentin and dental pulp, such as caries or trauma, involve the bacterial contamination of these tissues. Whereas local disinfection is important, antibacterial activity can also be programmed into the scaffold material. It is known that certain low-molecular-weight peptides show antibacterial activity (Brennan et al., 2006). High-throughput approaches allow for the screening of large numbers of appropriate peptide sequences to identify additional motifs with antibacterial activity. Peptide hydrogels can incorporate antimicrobial activity, for example, via lysine-rich surfaces, which facilitate electrostatic interaction of the peptide with the negatively charged bacterial surface, leading to disruption of the bacterial membrane (Salick et al., 2007). An additional means of contamination control might contribute to the elimination of bacteria in the root canal system, a requirement for successful new-tissue generation.

\section{CONCLUSION AND FUTURE PERSPECTIVE}

Self-assembling peptide systems are a promising class of biomaterials for tissue engineering, since they allow for a 'bottomup' approach of generating ECM-like materials, which offer high control at the molecular level and produce injectable materials ideally suited for small defects. They are an example of a tunable matrix, where features such as (1) matrix modulus, (2) sheer recovery, (3) cell adhesion motifs, (4) enzyme-cleavable sites for cell-mediated degradation, (5) controlled release of bioactive molecules, (6) mineral nucleation, and (7) antibacterial activity can be incorporated into the scaffold, thus making it a versatile, tailor-made matrix which could be highly useful for dentin-pulp engineering. With the recent results from transplantation experiments, optimized scaffolding systems might contribute toward the development of therapeutic strategies for regenerative endodontic approaches in the near future.

\section{ACKNOWLEDGMENTS}

The author(s) received no financial support and declared no potential conflicts of interests with respect to the authorship and/ or publication of this article.

\section{REFERENCES}

Aota S, Nomizu M, Yamada KM (1994). The short amino acid sequence Pro-His-Ser-Arg-Asn in human fibronectin enhances cell-adhesive function. $J$ Biol Chem 269:24756-24761.

Aulisa L, Dong H, Hartgerink JD (2009). Self-assembly of multidomain peptides: sequence variation allows control over cross-linking and viscoelasticity. Biomacromolecules 10:2694-2698.

Bhatnagar RS, Qian JJ, Gough CA (1997). The role in cell binding of a betabend within the triple helical region in collagen alpha 1 (I) chain: structural and biological evidence for conformational tautomerism on fiber surface. J Biomol Struct Dyn 14:547-560.

Bohl KS, Shon J, Rutherford B, Mooney DJ (1998). Role of synthetic extracellular matrix in development of engineered dental pulp. $J$ Biomater Sci Polym Ed 9:749-764.

Boontheekul T, Kong HJ, Mooney DJ (2005). Controlling alginate gel degradation utilizing partial oxidation and bimodal molecular weight distribution. Biomaterials 26:2455-2465.
Brennan EP, Reing J, Chew D, Myers-Irvin JM, Young EJ, Badylak SF (2006). Antibacterial activity within degradation products of biological scaffolds composed of extracellular matrix. Tissue Eng 12:2949-2955.

Cardin AD, Weintraub HJ (1989). Molecular modeling of proteinglycosaminoglycan interactions. Arteriosclerosis 9:21-32.

Chan G, Mooney DJ (2008). New materials for tissue engineering: towards greater control over the biological response. Trends Biotechnol 26: 382-392.

Cordeiro MM, Dong Z, Kaneko T, Zhang Z, Miyazawa M, Shi S, et al. (2008). Dental pulp tissue engineering with stem cells from exfoliated deciduous teeth. $J$ Endod 34:962-969.

Costello BJ, Shah G, Kumta P, Sfeir CS (2010). Regenerative medicine for craniomaxillofacial surgery. Oral Maxillofac Surg Clin North Am 22:33-42.

Dong H, Paramonov SE, Aulisa L, Bakota EL, Hartgerink JD (2007). Selfassembly of multidomain peptides: balancing molecular frustration controls conformation and nanostructure. J Am Chem Soc 129:12468-12472.

Galler KM, Cavender A, Yuwono V, Dong H, Shi S, Schmalz G, et al. (2008). Self-assembling peptide amphiphile nanofibers as a scaffold for dental stem cells. Tissue Eng Part A 14:2051-2058.

Galler KM, Aulisa L, Regan KR, D'Souza RN, Hartgerink JD (2010). Selfassembling multidomain peptide hydrogels: designed susceptibility to enzymatic cleavage allows enhanced cell migration and spreading. $J$ Am Chem Soc 132:3217-3223.

George A, Sabsay B, Simonian PA, Veis A (1993). Characterization of a novel dentin matrix acidic phosphoprotein. Implications for induction of biomineralization. $J$ Biol Chem 268:12624-12630.

Gloria A, De Santis R, Ambrosio L (2010). Polymer-based composite scaffolds for tissue engineering. J Appl Biomater Biomech 8:57-67.

Glowacki J, Mizuno S (2008). Collagen scaffolds for tissue engineering. Biopolymers 89:338-344.

Gronthos S, Mankani M, Brahim J, Robey PG, Shi S (2000). Postnatal human dental pulp stem cells (DPSCs) in vitro and in vivo. Proc Natl Acad Sci USA 97:13625-13630.

Hartgerink JD, Beniash E, Stupp SI (2001). Self-assembly and mineralization of peptide-amphiphile nanofibers. Science 294:1684-1688.

Hartgerink JD, Beniash E, Stupp SI (2002). Peptide-amphiphile nanofibers: a versatile scaffold for the preparation of self-assembling materials. Proc Natl Acad Sci USA 99:5133-5138.

He G, Dahl T, Veis A, George A (2003). Nucleation of apatite crystals in vitro by self-assembled dentin matrix protein $1-$ pp552 - 558. Nat Mater 8:552-558.

He H, Yu J, Liu Y, Lu S, Liu H, Shi J, et al. (2008). Effects of FGF2 and TGFbetal on the differentiation of human dental pulp stem cells in vitro. Cell Biol Int 32:827-834.

Huang GT, Yamaza T, Shea LD, Djouad F, Kuhn NZ, Tuan RS, et al. (2010). Stem/progenitor cell-mediated de novo regeneration of dental pulp with newly deposited continuous layer of dentin in an in vivo model. Tissue Eng Part A 16:605-615.

Ikeda E, Morita R, Nakao K, Ishida K, Nakamura T, Takano-Yamamoto T, et al. (2009). Fully functional bioengineered tooth replacement as an organ replacement therapy. Proc Natl Acad Sci USA 106:13475-13480.

Jakab K, Norotte C, Damon B, Marga F, Neagu A, Besch-Williford CL, et al. (2008). Tissue engineering by self-assembly of cells printed into topologically defined structures. Tissue Eng Part A 14:413-421.

Jiang T, Kumbar SG, Nair LS, Laurencin CT (2008). Biologically active chitosan systems for tissue engineering and regenerative medicine. Curr Top Med Chem 8:354-364.

Kim NR, Lee DH, Chung PH, Yang HC (2009). Distinct differentiation properties of human dental pulp cells on collagen, gelatin, and chitosan scaffolds. Oral Surg Oral Med Oral Pathol Oral Radiol Endod 108:e94-e100.

Levental I, Georges PC, Janmey PA (2007). Soft biological materials and their impact on cell function. Soft Matter 3:299-306.

Macchiarini P, Jungebluth P, Go T, Asnaghi MA, Rees LE, Cogan TA, et al. (2008). Clinical transplantation of a tissue-engineered airway. Lancet 372:2023-2030; erratum in Lancet 373:462, 2009.

Massia SP, Hubbell JA (1992). Vascular endothelial cell adhesion and spreading promoted by the peptide REDV of the IIICS region of plasma fibronectin is mediated by integrin alpha 4 beta $1 . \mathrm{J}$ Biol Chem 267:14019-14026 
Miura M, Gronthos S, Zhao M, Lu B, Fisher LW, Robey PG, et al. (2003). SHED: stem cells from human exfoliated deciduous teeth. Proc Natl Acad Sci USA 100:5807-5812.

Mooney DJ, Powell C, Piana J, Rutherford B (1996). Engineering dental pulp-like tissue in vitro. Biotechnol Prog 12:865-868.

Nemir S, West JL (2010). Synthetic materials in the study of cell response to substrate rigidity. Ann Biomed Eng 38:2-20.

Prescott RS, Alsanea R, Fayad MI, Johnson BR, Wenckus CS, Hao J, et al. (2008). In vivo generation of dental pulp-like tissue by using dental pulp stem cells, a collagen scaffold, and dentin matrix protein 1 after subcutaneous transplantation in mice. $J$ Endod 34:421-426.

Rajangam K, Behanna HA, Hui MJ, Han X, Hulvat JF, Lomasney JW, et al. (2006). Heparin binding nanostructures to promote growth of blood vessels. Nano Lett 6:2086-2090.

Rajangam K, Arnold MS, Rocco MA, Stupp SI (2008). Peptide amphiphile nanostructure-heparin interactions and their relationship to bioactivity. Biomaterials 29:3298-3305.

Ruoslahti E (1996). RGD and other recognition sequences for integrins. Annu Rev Cell Dev Biol 12:697-715.

Sakai VT, Zhang Z, Dong Z, Neiva KG, Machado MA, Shi S, et al. (2010). SHED differentiate into functional odontoblasts and endothelium. J Dent Res 89:791-796.

Salick DA, Kretsinger JK, Pochan DJ, Schneider JP (2007). Inherent antibacterial activity of a peptide-based beta-hairpin hydrogel. $\mathrm{J} \mathrm{Am} \mathrm{Chem}$ Soc 129:14793-14799.
Silva G, Czeisler C, Niece KL, Beniash E, Harrington DA, Kessler JA, et al. (2004). Selective differentiation of neural progenitor cells by highepitope density nanofibers. Science 303:1352-1355.

Stefani M (2010). Protein aggregation diseases: toxicity of soluble prefibrillar aggregates and their clinical significance. Methods Mol Biol 648: 25-41.

Takahashi K, Yamanaka S (2006). Induction of pluripotent stem cells from mouse embryonic and adult fibroblast cultures by defined factors. Cell 126:663-676.

Tye CE, Rattray KR, Warner KJ, Gordon JA, Sodek J, Hunter GK, et al. (2003). Delineation of the hydroxyapatite-nucleating domains of bone sialoprotein. J Biol Chem 278:7949-7955.

Vacanti JP, Langer R, Upton J, Marler JJ (1998). Transplantation of cells in matrices for tissue regeneration. Adv Drug Deliv Rev 33:165-182.

Villar CC, Cochran DL (2010). Regeneration of periodontal tissues: guided tissue regeneration. Dent Clin North Am 54:73-92.

Wells RG (2008). The role of matrix stiffness in regulating cell behavior. Hepatology 47:1394-1400.

Wong JY, Weng Z, Moll S, Kim S, Brown CT (2002). Identification and validation of a novel cell-recognition site (KNEED) on the 8th type III domain of fibronectin. Biomaterials 23:3865-3870.

Yamada Y, Kleinman HK (1992). Functional domains of cell adhesion molecules. Curr Opin Cell Biol 4:819-823.

Zhang S (2003). Fabrication of novel biomaterials through molecular selfassembly. Nat Biotechnol 21:1171-1178. 